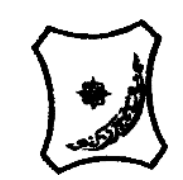

Bayero Journal of Pure and Applied Sciences, 14(1):17 - 20

Received: February, 2021

Accepted: April, 2021

ISSN $2006-6996$

\title{
SHORT COMMUNICATION EXTRACTION AND PHYTOCHEMICAL ANALYSIS OF Hyptis spicigera Leaves
}

\author{
Idi, A. ${ }^{1 *}$ and Muhammad, I. U. ${ }^{2}$ \\ ${ }^{1}$ Department of Biochemistry, Faculty of Basic Medical Sciences, Bayero University Kano, P.M.B.3011, \\ Kano, Nigeria. \\ ${ }^{2}$ Department of Medical Biochemistry, College of Medical Sciences, Yobe State University, Damaturu, \\ P.M.B 1144; Yobe, Nigeria. \\ *Corresponding author:amin2idi66@gmail.com
}

\begin{abstract}
Plants are recognized in the pharmaceutical industry for their broad structural diversity as well as their wide range of pharmacological activities, which is due to their biologically active compounds known as phytochemicals. The present study reports the extraction, thin layer chromatography and screening of phytochemical constituent of Hyptis spicigera leaves. The thin layer chromatography of the leave extract shows 11 bands with $R_{f}$ values of $0.03,0.06,0.09,0.12,0.17,0.19,0.20,0.23$ and 0.31 respectively. Qualitative phytochemical screening showed the presence of alkaloids, flavonoids, steroids, emodins, and cardiac glycoside while phenols, tannins, terpenoids, tri terpenoids and anthraquinones were absent. The presences of these phytochemicals showed that Hyptis spicigera leaves may be useful for medicinal purpose.

Keywords: Hyptis spicigera; extraction; thin layer chromatography and phytochemical screening.
\end{abstract}

\section{INTRODUCTION}

Medicinal plants are the back bone of traditional medicine. The use of plant preparation for treatment and prevention of ailments traditionally depends on experience and superstitious beliefs passed from generation to generation, virtually by the word of mouth. Researches on medicinal plants are on the increase globally. Various parts of medicinal plants (stem, bark, seeds, leaves and roots) have been used in various systems as they have potential effects against numerous diseases. Medicinal plants have been used as a source of medicine to treat/manage diseases for centuries (WHO, 2016). However, a great number of plants in Nigeria are noted traditionally for their medicinal properties, but only few have so far been studied for their active constituents, some plant extracts could be inherently dangerous, containing naturally occurring toxins, which may be cytotoxic or carcinogenic.

Hyptis spicigera commonly known as bush mint in English is a member of lamiaceae family. It is a strong aromatic plant and may be herbaceous annual or perennial plant of $0.5-1 \mathrm{~m}$ high (Uraku et al., 2015). In Nigeria, it is known as Bunsuru fadama in Hausa, Ogwuawunta in Igbo and Ogunefon in Yoruba (Lambert et al. 1985). The plant possesses very tiny brown and black seeds that clustered In groups of four, five or even more which are encased in each flower that make up inflorescence (Ladan et al., 2014). Hyptis spicigera is widespread in tropical North and South America as well as part of West Africa (Conti et al., 2011). Also, it is distributed in tropical and warm temperature region. It grows naturally in roadside, waste and damp places as wellas in farmland. Hyptis spicigera leaves are used as a spray to keep and protect crops from various insect attacks and are place in a layer below bundle of millet to keep away termites (Jirovetz et al., 2000).

Hyptis spicigera was reported to be used as food especially among the Kakwa tribe from Yei in South Sudan, the seeds are used for oil production whereas the leaves are eaten avegetables and spices (Ladan et al., 2011). The leaves were also reported to be used as treatment of upper respiratory tract infection, diarrhea, headache, pneumonia fever and cholera (Baba et al., 2012).

This study was aimed at extracting and fractionating the bioactive components from the leaves of this plant using chloroform and thin layer chromatography respectively, as well as to screen the phytochemicals present. 
BAJOPAS Volume 14 Number 1, June, 2021 MATERIALS AND METHODS Collection and Extraction of the Plant Material

The fresh leaves of Hyptis spicigera was collected from a herbarium in Tsamiyar Ziri, along Daura road, Minjibir Local Government Area of Kano state, Nigeria. It was authenticated by a taxonomist from Department of Plant Science, Bayero University, Kano. The leaves were dried under shade and ground into powder using a pestle and mortar.

The extraction was carried out using Soxhlet extractor. Sixteen and half $(16.5 \mathrm{~g})$ of the pulverized sample was packed in a cheesecloth bag known as extraction thimble. Chloroform was used for the extraction process until a clear solvent was obtained from the thimble. The filterate was collected and solvent evaporated to dryness.

$\mathrm{Rf}_{\mathrm{f}}=\frac{\text { Distance travelled by compound from origin }}{\text { Distance travelled by solvent from origin }}$ Phytochemical Screening

Phytochemical tests were carried out by using the standard methods of Sofowora (1993), Parekh and Chanda (2009), Trease and Evans (1989) and El- Olemyl et al(1994).

\section{Thin Layer Chromatography (TLC)}

Fractionation of the chloroform extract was done using a precoated $20 \mathrm{~cm} \times 20 \mathrm{~cm}$ TLC plate. Five grammes $(5 \mathrm{~g})$ of the dried extract was dissolved in chloroform and spotted on the plate $2 \mathrm{~cm}$ from the base. The plate was allowed to dry at room temperature and lowered in a chromatographic tank containing the solvent system saturated with the solvent vapour. The solvent was allowed to ascend the plate until the solvent front reaches about $3 / 4$ of the length of the plate. The plate was removed and allowed to dry at room temperature. It was then viewed under UV light to detect the bands. Thereafter, each band was scraped off for phytochemical screening of the compound. The relative retention factor (Rf) was calculated according to the relation below:

\section{RESULTS AND DISCUSSION}

Plate 1 shows the fractionation of the extract using thin layer chromatography preparatory plate. The plate shows eleven band with various Rf values.

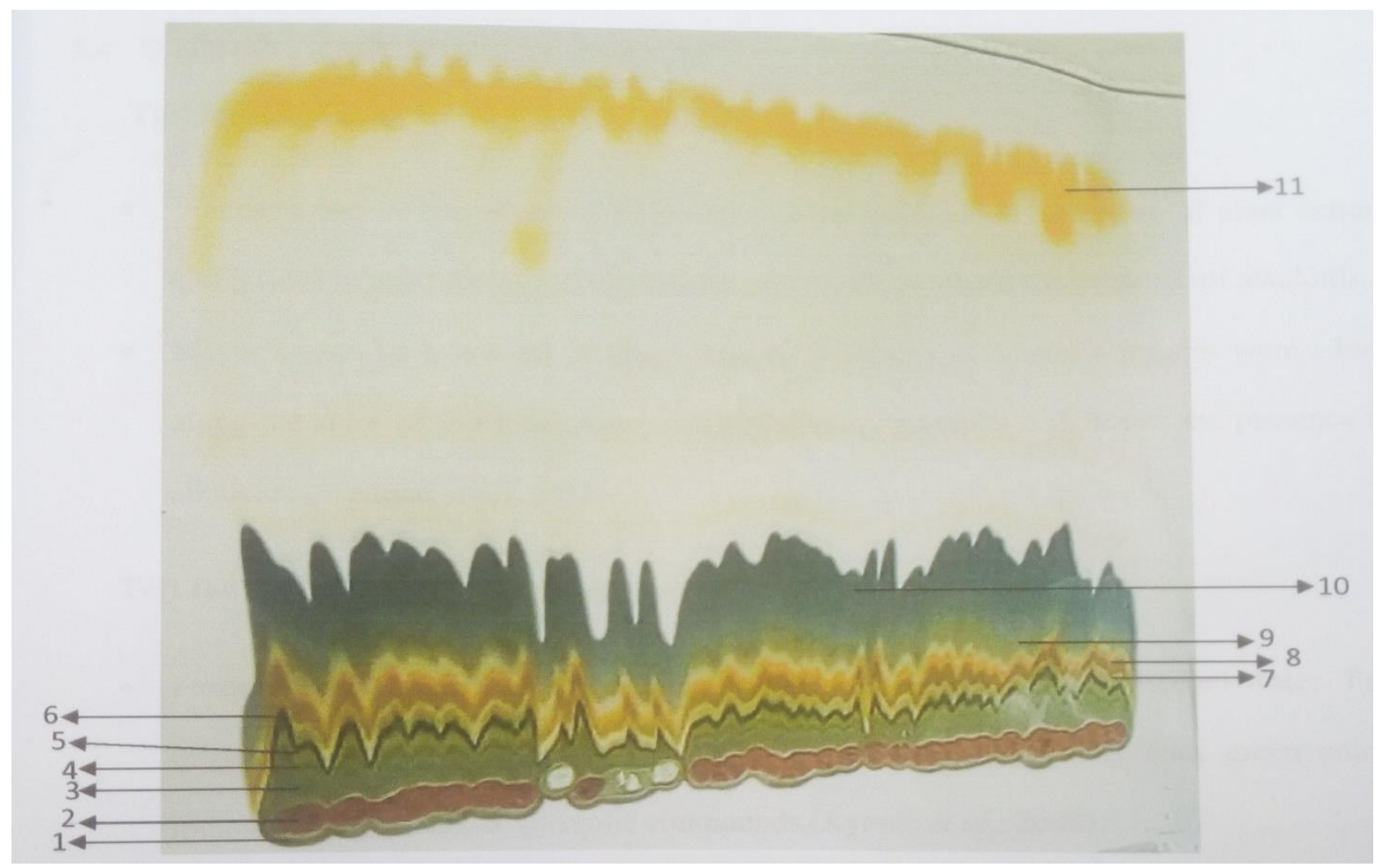

Table 1 present the result for phytochemical screening of various band obtained from thin layer chromatography. The screening showed the presence of alkaloids, flavonoids, steroids, emodins, and cardiac glycoside while phenols, tannins, terpenoids, triterpenoids, saponin and anthraquinones were absent. 
Table 1: Qualitative Phytochemical screening of Hyptis spicigera leaves

\begin{tabular}{llllllllllll}
\hline Bands & Alk & Terp & Sap & Tan & Ph & Em & Ste & Fla & Ant & Tri & glycoside \\
\hline Base band & + & - & - & - & - & - & + & + & - & - & - \\
Band 1 & - & - & - & - & - & - & + & - & - & - & - \\
Band 2 & - & - & - & - & - & - & - & - & - & - & - \\
Band 3 & - & - & - & - & - & - & - & - & - & - & - \\
Band 4 and & - & - & - & - & - & + & - & - & - & - & + \\
5 & & & & & & & & & & & - \\
Band 6 and & - & - & - & - & - & - & - & - & - & - & - \\
7 & & & & & & & & & & - & - \\
Band 8 & + & - & - & - & - & + & + & - & - & - & - \\
Band 9 and & - & - & - & - & - & - & + & + & - & - & - \\
10 & & & & & & & & & & - & -
\end{tabular}

Key: + present; - absent. Alk $=$ Alkaloids, Terp $=$ Terpenoids, Sap $=$ Saponins, Tan $=$ Tannins, Ant $=$ Anthraquinones, $\mathrm{Em}=$ emodins, $\mathrm{Ph}=$ phenols, $\mathrm{Tri}=$ Triterpenoids, Ste $=$ Steroids

\section{DISCUSSION}

Phytochemical compounds are synthesized by primary or secondary metabolism of plants. Secondary metabolites are taxonomically and chemically diverse compounds with huge function which are extensively used in agriculture, human therapy, veterinary and related scientific research (Mansoor et al., 2011). Hyptis spicigera leaves was shown to contain some vital phytochemicals such as alkaloids, flavonoids, steroids, emodins, and cardiac glycoside which might be responsible for the acclaimed medicinal properties of the plant. Onayade et a/(1991) reported the presence of similar class of phytochemicals with the absence of Emodins, this might be due to the difference in solvents used during the extraction process.

Numerous methods have been utilized in drug discovery, including isolation of compounds from plants and other natural sources, synthetic chemistry, combinatorial chemistry and molecular modeling (Geysen et al., 2003; Lombardino and Lowe, 2004). Despite the recent

\section{REFERENCES}

Baba, M.F., Akpagana, K. and Bouchet, P. (2012). Antifungal activities of seven west African combretacecae used in traditional medicine. Journal of Ethnopharmacology. 66:335-338.

Butler, M.S. (2004). The role of natural product chemistry in drug discovery. Journal of Natural Products 67 (12): 2141-2153.

Conti, B. Canale, A., Cioni, P.C., Flamini,G., Rifici, A. (2011). Hyptis and Hyptis spicigera (lamiacea) essential oil: quantitative analysis, contact toxicity and repellant activity against Sitophilus granaries (L). Journal of Pest Science. 84:219-228. interest of pharmaceutical companies and funding organizations in molecular modeling, combinatorial chemistry and other synthetic chemistry techniques, natural products (in particular, medicinal plants), remain an important source of new drugs which leads to new chemical entities (NCEs) (Newman et al., 2000; Butler, 2004). Fractionation of the leaves extract therefore leads to eleven band of different phytochemical constituents, with the base band possessing alkaloids, flavonoids and steroids while band 8 possess alkaloids, emodins and steroids. Thus, these bands might have potentials to be used in further characterization and isolation of biologically active compounds from the leaves.

\section{CONCLUSION}

The results of the present study showed Hyptis spicigera leaves extract possess various phytochemicals which may be responsible for the reported pharmacological activities of the plant.

El-Olemy, M., M., Al-muhdtadi, F., J., and Afifi, A., A. (1994). Experimental Phytochemistry. A laboratory manual. Published by King Saudi University Prees $5^{\text {th }}$ ed. Pp 247.

Geysen, H.M., Schoenen, F., Wagner, D. and Wagner, R. (2003). Combinatorial compound libraries for drug discovery: an ongoing challenge. Nature Reviews Drug Discovery 2 (3):222-230.

Jirovetz, L., Buchbauer, G., Paschwwann, C. and Ngassoum, M.B. (2000). Investigation of aromatic plants from Cameroon. Analysis of the essential oils of flowers of Hyptis spicigera by GC, GC/MS and olfactometry. Journal of essential oil bearing plants. 3:71-77. 
BAJOPAS Volume 14 Number 1, June, 2021

Ladan Z., Amupitan J.O., Oyewale O.A, Okonkwo, M.E., Ladan E.O., Odjobo B. and Habila N. (2011). Chemical composition and Biological activity of the volatile oils of Hyptis spicigera against Trypanosoma brucei found in northern Nigeria. African Journal of Pure and Applied Chemistry. 5(4): 53-58.

Ladan Z., Amupitan J.O., Oyewale O.A, Temple E. and Ladan E.O. (2014). phytochemical screening of the leaf extract of Hyptis spicigera plant. African journal of pure and Applied Chemistry. 8(5): 1996-2001.

Lambert, J., Arnason J.T. and Philoge B.J.R (1985). Bruchid control with traditionally used insecticidal plant Hyptis spicigera and cassia nigricans. Insect science and its application 6:167-170.

Lombardino, J.G. and Lowe, J.A. (2004). The role of the medicinal chemist in drug discovery: Then and now. Nature Reviews and Drug Discovery 3(10), 853862.

Mansoor, A., Ibrahim, M., A., Zaidi, M., A., Ahmed, M. (2011). Antiprotozoal activities of Carum copticum Bangl. J Pharmacol. 6:51-54

Newman, D.J., Cragg, G.M. and Snader, K.M. (2003). Natural products as sources of new drugs over the period 1981-2002. Journal of Natural Products 66 (7): 1022-1037.
Onayede, O.A., Looma, A., Scheffer, J.J. and Svendesn, A.B. (1991). Composition of the leaf essential oil of Hyptis spicigera. Flavor and Fragrance Journal. 5:101105.

Parekh, J., and Chanda, S. U. (2007). In- vitro antimicrobial activity and phytochemical analysis of some Indian medicinal plants. Turk J Biol. 31:53-58

Sofowora, A. (1993). Medicinal Plants and Medicine in Afric. John Willey Spectrum, Ibadan-Nigeria. 2: $81-85$.

Toma I., Karumi Y., and Geidam M., A. (2009). "Phytochemical screening and toxicity studies of the aqueous extract of the pods pulp of Cassia sieberiana D.C. African journal of pure and applied chemistry. 3(2): 026-030.

Trease, G.E. and Evans, W.C. (1989). Pharmacognosy. A physician guide to herbal medicine, 11edn. Ballere Tindal, London, UK, pp 530.

Uraku, A.J., Okaka. A.N.C., Ibiam, U.A., Agbafor, K.N., Ajah, P.M. and Nweke, F.N. (2015). Evaluation and a chemical composition of Ocimum baslicum and Hyptis spicigera leaves. Ebsu Journal of Nature. 1:21-33.

WHO (2016). Legal status of Traditional Medicines and Complementary/ Alternative Medicine. A worldwide review. WHO publishing1. 